\title{
Has the quality of physiotherapy care in patients with Whiplash-associated disorders (WAD) improved over time? A retrospective study using routinely collected data and quality indicators
}

This article was published in the following Dove Press journal:

Patient Preference and Adherence

Rob AB Oostendorp, ${ }^{1-4}$ Hans Elvers, ${ }^{5,6}$ Emiel van Trijffel, 7,8 Geert M Rutten,, 910 Gwendolyne GM Scholten-Peeters," Marcel Heijmans, ${ }^{4}$ Erik Hendriks, ${ }^{2,13}$ Emilia Mikolajewska, ${ }^{14,15}$ Margot De Kooning, ${ }^{3,8,16}$ Marjan Laekeman, ${ }^{17}$ Jo Nijs, ${ }^{3,8,16}$ Nathalie Roussel, ${ }^{18}$ Han Samwel ${ }^{19}$

'Scientific Institute for Quality of Healthcare, Radboud University Nijmegen Medical Centre, Nijmegen, the Netherlands; '2 Department of Manual Therapy, Faculty of Medicine and Pharmacy, Vrije Universiteit Brussel, Brussels, Belgium; ${ }^{3}$ Pain in Motion International Research Group. Free University Brussels, Brussels, Belgium; ‘Practice Physiotherapy and Manual Therapy, Heeswijk-Dinthe the Netherlands; ${ }^{5}$ Department of Public Health and Research, Radboud University Nijmegen Medical Centre, Nijmegen, the Netherlands; ${ }^{\circ}$ Methodological HealthSkilled Institute, Beuningen, the Netherlands; ${ }^{5} \mathrm{SOM}$ University of Physiotherapy, Amersfoort, the Netherlands; ${ }^{8}$ Department of Physiotherapy, Human Physiology and Anatomy, Faculty of Physical Education and Physiotherapy. Free University Brussels, Brussels, Belgium; 'Institute of Health Studies, Faculty of Health and Social Studies, HAN University of Applied Science, Nijmegen, the Netherlands; ${ }^{10}$ Faculty of Science and Engineering University College Venlo, Maastricht University, Maastricht, the Netherlands: "Departent of Human Movement Sciences, Faculty of Department of Human Movement Sciences, Faculty of Amstord A of Epidemiology, Center of Evidence-Based Physiotherapy, Maastricht Universicy, Maastricht, the Netherlands, Physiotherapy 'Klepperheide', Druten, the Netherlands; ${ }^{14}$ Department of Physiotherapy, Ludwik Rydygier Collegium Medicum in Bydgoszcz, Nicolaus Copernicus University

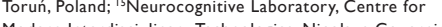
Modern Interdisciplinary Technologies, Nicolaus Copernicus University, Torun, Poland; ' ${ }^{6}$ Department of Physical Medicin and Physiotherapy, University Hospital Brussels, Brussels, Belgium; "Department of Nursing Sciences, Faculty of Health, University Witten/Herdecke, Witten, Germany; ${ }^{18}$ Department of Rehabilitation Sciences and Physiotherapy (MOVANT), Faculty of Medicine and Health Sciences, University of Antwerp, Belgium; 'DDepartment of Medical Psychology, Canisius Wilhelmina Hospital, Nijmegen, the Netherlands

Correspondence: Rob AB Oostendorp Radboud University Nijmegen Medical Centre, Scientific Institute for Quality of Healthcare (IQ Healthcare) p/a Oude Kleefsebaan 325,

6572 AT Berg en Da

the Netherlands

$\mathrm{Tel}+3 \mid 246423419$

Email oostendorp.rob@gmail.com
Purpose: To develop valid quality indicators (QIs) for physiotherapy care based on best available evidence, and to use these QIs to explore trends in the quality of physiotherapy care of patients with Whiplash-associated disorders (WAD) using guideline-based routinely collected data (RCD) gathered between 1996 and 2011.

Materials and methods: The study consisted of two phases: 1) development of QIs and 2) analysis of patient records. A set of QIs was developed based on recommendations in the scientific literature and the Dutch Clinical Practice Guideline (CPG) "Physiotherapy Management and WAD”. QIs were expressed as percentages, allowing target performance levels to be defined ( $\geq 80 \%$ or $\leq 30 \%$ depending on whether desired performance required a high or low score on a QI). We then analyzed WAD patient data $(\mathrm{N}=810)$ collected over a period of 16 years in two physiotherapy practices, separating patients into two groups defined as before (Group A 1996-2002; $\mathrm{n}=353$ ) and after (Group B 2003-2011; $\mathrm{n}=457$ ) implementation and transition to the Dutch CPG "Physiotherapy Management and WAD".

Results: Using an iterative process and input from both experts and users, 28 QIs were developed and subsequently classified per step of the clinical reasoning process for physiotherapy care. Based on 16 years of RCD, we found that the clinical reasoning process differed significantly $(P \leq 0.05)$ between the groups, in favor of Group B. Twelve of the 25 indicators $(48.0 \%)$ in Group A and 19 of 26 indicators (73.1\%) in Group B met predetermined performance targets. The number of target indicators also differed significantly between groups, favoring Group $\mathrm{B}$ $(P \leq 0.05)$.

Conclusion: A preliminary set of novel QIs was developed. Using RCD and these QIs, we conclude that physiotherapy care in our study setting improved over the period 1996-2011. Furthermore, the QIs met the performance targets set for the clinical reasoning process after the transition to the Dutch CPG "Physiotherapy Management and WAD".

Keywords: quality of physiotherapy care, Whiplash-associated disorders, clinical guidelines, quality indicators, clinical reasoning process, routinely collected data

\section{Introduction}

Current national and international Clinical Practice Guidelines (CPGs) for patients with Whiplash-associated disorders (WAD) are mainly based on the results of systematic reviews and on primary studies of diagnostics, prognostics, and treatment. ${ }^{1-12}$ In general, comparable recommendations can be found in these guidelines, all of which are based on weak or moderate levels of evidence. 
Due to the lack of high-quality supporting evidence and a limited understanding of how well CPGs for physiotherapy management and WAD are implemented in daily practice, ${ }^{13,14}$ patients may currently receive suboptimal or even inappropriate physiotherapy diagnostics and treatment. ${ }^{15}$ This, in turn, may result in negative health consequences and higher societal costs.

The CPG "Physiotherapy Management and WAD" was introduced between $2001^{2}$ and 2002. ${ }^{3}$ In contrast to international CPGs, ${ }^{4-6,9,11}$ Dutch CPGs are generally based on a nine-step clinical reasoning process. Clinical reasoning has been defined "as a process in which the physiotherapist, interacting with the patient and significant others, structures meaning, goals and health management strategies based on clinical data, client choices and professional judgment and knowledge". ${ }^{16,17}$ The clinical reasoning cycle is an internationally accepted concept to facilitate problem solving and decision making in daily practice. The transparency of the clinical reasoning process, as provided by measurable elements such as quality indicators (QIs), is considered a cornerstone of the quality of care. ${ }^{18}$

QIs have been defined as "measurable elements of practice performance for which there is evidence or consensus that they can be used to assess the quality of the care provided."19 QIs may relate to structures (such as staff, equipment, appointment systems), processes (such as clinical reasoning), or outcomes of care (such as a patient's functioning or disability). ${ }^{20}$ QIs can be used to analyze and evaluate the quality of physiotherapy care of patients with $\mathrm{WAD}$, and the systematic development of QIs is preferably centered on guideline-based recommendations, supplemented by expert clinical experience and patient perspectives. Process and outcome indicators are often based on patient registration systems that encompass operationalized guideline-based recommendations as measurable elements of clinical practice. ${ }^{18-20}$ It is also generally accepted that the quality of patient registration systems is a reliable indicator of the quality of care. ${ }^{21}$

Despite the fact that a large proportion of WAD patients are managed by physiotherapists, only limited data are available on the quality of the physiotherapy care process. Furthermore, there is still little data or understanding of the complexity of the clinical reasoning process in patients with $\mathrm{WAD}$, a deficiency that may hamper quality improvements for physiotherapy in primary care., ${ }^{9,15}$

One promising approach to the assessment of the quality of physiotherapy care for patients with WAD is exploration of routinely collected data (RCD). ${ }^{22} \mathrm{RCD}$ has several distinct advantages, since data collection during routine clinical practice maximizes representativeness, minimizes costs, and allows capture of information from a large population. These data include many clinical events occurring in large data sets that are continuously updated over long periods and as such form the basis of the present study.

Using a novel set of QIs developed specifically for this study, our overall aim was to explore trends in the quality of physiotherapy care in patients with WAD over a period of 16 years (1996-2011) using structured, detailed, and systematically gathered RCD. We anticipated that these novel QIs, together with high-quality, long-term RCD, would allow us to track trends in the quality of physiotherapy care following the dissemination and transition to the Dutch CPG Physiotherapy Management and WAD in 2002.

\section{Materials and methods Design}

This retrospective cohort study, based on RCD that cover a period of 16 years (1996-2011), was carried out in two primary care physiotherapy practices in the Netherlands, specialized in assessments in patients with WAD.

The Medical Ethics Committee of Radboud University Medical Center, Nijmegen, in the Netherlands waived in writing the requirement for ethical approval as our study involved routinely collected clinical data that represented no extra burden for patients.

As members of the steering committee of the project Quality of Physiotherapy and WAD, we agree to conduct ourselves in strict conformance with all applicable laws and with the polices of the Royal Dutch Association of Physiotherapy regarding patient data confidentiality and security. These obligations apply to confidential information that is collected or maintained verbally, in paper, or electronic format.

For the purposes of the study, we divided the collected data into two groups: one detailing care before (Group A 1996-2002) and the second after (Group B 2003-2011) the implementation of the Dutch CPG Physiotherapy Management and WAD.

\section{Phases}

The study protocol comprised two distinct phases: 1) indicator development and 2) analysis of WAD patient records. The assembled data included variables on all steps of the physiotherapy clinical reasoning process, including I: Administration, II: History taking, III: Objectives of examination, IV: Clinical examination, V: Analysis and conclusion, VI: Treatment plan, VII: Treatment, VIII: Evaluation and IX: Discharge. All items describing each step of the clinical reasoning process, except for medical information 
and specific care needs, were collected in a closed format patient record. The physiotherapy modalities were coded according to the Classification of Physiotherapy, which distinguishes nine modalities: 1) History taking; 2) Inspection and observation; 3) Palpation; 4) Active exercise therapy; 5) Passive exercise therapy/manual therapy; 6) Massage therapy; 7) Modalities of physical therapy (ie, low- and highfrequency electrotherapy); 8) Coaching; and 9) Education. ${ }^{23}$ Patient records were outlined in accordance with the national $\mathrm{CPG}$ regarding requirements for physiotherapy documentation. ${ }^{24}$

A systematic RAND-modified Delphi method, including independent expert comments and iterative feedback, was used to develop a set of recommendations suitable for transcription into QIs. ${ }^{18,25}$ The method of QI development included five steps: 1) extraction of recommendations from literature and guidelines; 2) transformation of recommendations into indicators; 3) appraisal of a preliminary set of indicators by an expert and user panel with consensus; 4) classification of process indicators; and 5) classification of outcome indicators.

\section{Phase I: indicator development}

Step I: extraction of physiotherapy and WAD-related recommendations

The first group of recommendations was derived from the 1995 Quebec Task Force on WAD. ${ }^{1}$ A second group of 2001/2002 recommendations for physiotherapy management of WAD was extracted from the Dutch CPG Physiotherapy Management and Whiplash, ${ }^{2,3}$ and a third group of recommendations was identified using more recently published (2009) international guidelines ${ }^{4-6}$ and publications concerning pain modulation and central sensitization in patients with WAD. ${ }^{26-30}$ In addition, we used existing relevant information from the Bone and Joint Decade 2000-2010 Task Force on Neck Pain and Its Associated Disorders, ${ }^{31}$ orthopedic textbooks, ${ }^{31-36}$ and core sets for musculoskeletal disorders of the International Classification of Functioning, Disability, and Health (ICF)..$^{37,38}$ These recommendations were extracted by two members of the research team (RABO and $\mathrm{MH}$ ) and, if necessary, differences were discussed with a third member of the team $(\mathrm{EH})$ until consensus was reached. Previously formulated recommendations were compared against current evidence and updated using new recommendations when necessary.

\section{Step 2: transformation of recommendations into Qls}

The recommendations were transformed into QIs by phrasing them as the average degree (in \%) to which patients were subjected to a methodically performed clinical reasoning process (eg, the average degree to which patients were subjected to a methodically performed history taking).

\section{Step 3: appraisal by an expert and user panel}

Steps 1 and 2 were followed by an online survey of a panel of experts $(n=27)$, including physical therapists specialized in musculoskeletal PT, particularly WAD $(n=15)$, clinical epidemiologists $(n=3)$, developers of physiotherapy CPGs $(n=3)$, psychologists $(n=4)$, and neurologists $(n=2)$. The panel was asked to score the set of QIs on a five-point Likert scale ( $1=$ not at all to $5=$ completely), based on their clarity and relevancy to the physiotherapy care process. The results were discussed in the steering committee, using a standardized consensus criterion (clarity and relevancy scores 4 and 5). In a second online survey, the set of selected QIs was subsequently presented to a user panel of physiotherapists working in private practices $(n=15)$ who scored the indicators on a five-point Likert scale $(1=$ not at all to $5=$ completely), based on feasibility and acceptability. Again, the results were discussed in the steering committee using a similar standardized consensus tool (feasibility and acceptability scores 4 and 5). We anticipated that this procedure would produce a set of QIs with content validity.

\section{Step 4: classification of process indicators}

The process indicators, including the type of indicator (process generic or specific, outcome generic, number of items per indicator, and level of evidence), were classified into nine domains according to the previously mentioned steps of the clinical reasoning process in physiotherapy care.

The level of research evidence for the formulated QIs, from levels I to IV, was determined based on a national consensus document, ${ }^{39}$ with level I being the highest: level $\mathrm{I}=$ systematic review or $>2$ high-quality controlled trials or high-quality diagnostic studies or high-quality psychometric studies; level II = two high-quality controlled trials or highquality diagnostic studies or high-quality psychometric studies; level III = high-quality non-controlled trials or low-quality diagnostic studies or low-quality psychometric studies; level IV = expert opinion and professional consensus or standard.

\section{Step 5: classification of outcome indicators}

Based on recommended standard outcome measures and on psychometric quality, the outcome indicators consisted of scores for a variety of patient-reported outcome measures, including measures of neck pain intensity, functioning or disability, and global perceived effect (GPE). ${ }^{40}$ The outcome 
indicators were classified in accordance with the ICF as body functions (head and neck pain) and activities and participation (eg, mobility, self-care, domestic life, work, employment). ${ }^{37,38}$ Pain intensity was measured using the Visual Analog Scale for Pain (VAS-P), which consists of a $100 \mathrm{~mm}$ line scored from 0 (no pain) to 100 (worst imaginable pain). ${ }^{41}$ Functioning-related outcome measures included the Neck Disability Index (NDI). ${ }^{42-45}$ The NDI consists of 10 questions, scored $0-5$, with increasing scores representing functional impairment and disability due to neck pain. Patients were asked to evaluate treatment GPE, rating the pre- to postintervention change in GPE from 1 (complete resolution) to 6 (clearly worsened). ${ }^{45}$ The QIs for outcome measures in this part of the study consisted of the average degree to which the recommended outcome measurements were applied. In addition to these outcome measures, the duration of the treatment episode in weeks and the number of treatment sessions were both recorded as outcome indicators.

\section{Phase II: RCD Data collection}

Data on WAD patients were collected over a period of 16 years in the form of a pen and paper patient record that guided the steps of the clinical reasoning process of care. The first WAD patient record was developed in 1995 using the Quebec Task Force WAD ${ }^{1}$ and was updated in 2002 using the Dutch CPG Physiotherapy Management and WAD, 2,3 and further modernized in 2009 using both international guidelines ${ }^{4-6}$ and evidence concerning pain modulation and central sensitization in patients with WAD. ${ }^{28,29,46}$ Patients with a history, signs, and symptoms suggestive of potentially serious pathology (red flags), including an initial interview related to the 5 D's +1 (dizziness, diplopia, drop attack, dysarthria, dysphagia, plus nausea), were excluded from the analysis. Red flags are signs and symptoms that may indicate a specific pathology due to injury. ${ }^{34}$ The registration of data on otoneurological and psychological examinations started in 2000, pre- and posttreatment measures of pain, functioning or disability, and GPE began in 2002, psychological questionnaires and arrangement of aftercare in 2003, and registration of signs indicting central sensitization began in 2009. See flowchart for the latest version of the clinical reasoning process (see Supplementary $\mathrm{S} 1$ ).

In 1996, the first WAD patient record was introduced in two Dutch primary care physiotherapy practices with eight participating physiotherapists, and no reimbursement or compensation for their participation was involved. The following characteristics of the physiotherapists were noted: age, gender, practice experience with patients with WAD, and specialization in manual physiotherapy. The participating physiotherapists received updates in accordance with adjustments to the content of the patient records, explained during three 3-hour meetings that took place in 2001, 2002, and 2009. They also received instructions on how to score the items of each step of the clinical reasoning process. All patient records were archived.

\section{Data analysis}

In 2016, we started a quality improvement study on primary care physiotherapy management and WAD using an existing large data set. After cleaning and processing of the data set, the analysis was carried out retrospectively.

Most of the variables for the two periods 1996-2002 and 2003-2011 were collected in a similar way, allowing comparison. Algorithms that followed the clinical reasoning process in patients with WAD (see flowchart in Supplementary S1) were formulated to translate the data into scores on QIs. QIs were expressed as frequencies, allowing target performance to be defined. ${ }^{18}$ See formula in Figure 1.

QIs were scored as percentages, yielding possible scores for quality of care ranging from 0 to 100 . The performance target for 23 indicators was set to $\geq 80 \%$ (indicators $1-4$, $8-15$, and $17-27$ ), to $\leq 30 \%$ for three indicators $(5-7)$ depending on whether desired performance target required a high or low score on the indicator (preexistent functioning, preexistent health status before injury, and previous diagnostics and treatment), and was "nondefined" for two indicators (indicators 16 and 28) due to the innovative character of these indicators. ${ }^{30,47}$ The analytical software program Statistix 9 was used for descriptive statistics.

Descriptive statistics were used to characterize the patient population and QI percentages. Differences between patient characteristics on dichotomous variables and means of QIs between the groups were tested using a chi-squared test. Twosample $t$-tests were used to test differences in continuous data between the groups. Statistical significance was set at $\alpha=0.05$. An overview of all variables for analysis per clinical reasoning step is presented in Supplementary $\mathrm{S} 2$.

$$
\text { Indicator } \mathrm{x}=\left(\frac{\frac{\sum I}{N_{k}}}{N_{j}}\right) \times 100 \%
$$

Figure I Formula for frequency of indicator $\left(\sum l=\right.$ sum scores of items per indicator, $N_{k}=$ number of items per indicator, and $N_{j}=$ number of respondents per year). 


\section{Results}

\section{Phase I: indicator development}

Step I: guideline-based recommendations

In total, 125 literature- and guideline-based items were extracted in relation to the total clinical reasoning process in patients with WAD. After critical evaluation and checking for duplication and overlap by two members of the project group (RABO and $\mathrm{MH}$ ), the number of preselected items was reduced to 96 items covering the nine steps of the physiotherapy clinical reasoning process: I. Administration $(n=6)$; II. History taking $(\mathrm{n}=35)$; III. Objectives of examination $(\mathrm{n}=4)$; IV. Clinical examination $(\mathrm{n}=16)$; V. Analysis and conclusion $(n=14)$; VI. Treatment plan $(n=5)$; VII. Treatment $(n=2)$; VIII. Evaluation $(n=11)$; IX. Discharge $(n=3)$ (see Supplementary S2).

\section{Step 2: QIs}

The remaining 96 items were transformed into 28 QIs, including both process and outcome indicators, by phrasing them as the average degree $(\%)$ to which patients were subjected to a methodically performed clinical reasoning process. For example, the average degree (in \%) to which patients underwent a methodically performed history taking, the average degree to which accident-related information was noted, the average degree to which treatment goals were determined and recorded in agreement with individual prognostic health profiles and the time phase since an accident, and the average degree to which physiotherapy modalities agreed with treatment goals and with time phases since an accident.

\section{Step 3: expert and user appraisal of QIs}

The expert panel $(n=27)$ evaluated the preliminary set of 28 QIs as being clear and precise, with unambiguous language. The experts judged all indicators to be (very) relevant in the clinical reasoning process (scores 4 and 5 on a five-point Likert scale). The user panel $(n=15)$ evaluated the 28 QIs as completely clinically acceptable and feasible (score 5 on a five-point Likert scale). This procedure resulted in a set of 28 QIs with content validity and accompanying criteria.

\section{Step 4: classification of Qls}

The QIs were classified per step of the clinical reasoning process in physiotherapy care, including the level of evidence. A complete overview of these 28 indicators per step of the clinical reasoning process is presented in Supplementary S3 and includes type of indicator, the number of items, the level of evidence, and the performance target per indicator. QI 19 was supported by level I evidence; indicator 20 by level II evidence; indicators 11,14 , and 15 by level II-IV evidence; and indicators $1-10,12,13,16-18,21,27,28$ by level IV evidence.

\section{Step 5: classification of outcome indicators}

In the case of step VIII "Evaluation", four outcome indicators were classified including: subjective evaluation of treatment goals and return to work (indicators 22 and 23), objective evaluation of posttreatment measures of pain (VAS) and functioning (NDI) (indicator 24), GPE (indicator 25), and duration of treatment, period, and number of treatment sessions (indicator 26). Indicators 24 and 25 were supported by levels I and II evidence, respectively, and indicators 22, 23, and 26 by level IV evidence.

\section{Phase II: RCD}

Eight physiotherapists at two primary care physiotherapy practices in the South of the Netherlands collected data over a period of 16 years. The mean age of the physiotherapists $(n=8)$ at the beginning of the study was 46.2 years $(\mathrm{SD}=5.6)$, six were male and six were manual physiotherapists. The range of practice experience regarding patients with WAD varied between 6 and 28 years.

The number of referrals per year is presented in Figure 2. In total, 810 patients were referred by a GP $(n=549)$ or by a medical specialist $(n=164)$ or were self-referred (open access to physiotherapy was introduced in the Netherlands in 2005) $(\mathrm{n}=97)$. Following an initial interview related to the 5 D's +1 (dizziness, diplopia, drop attacks, dysarthria, dysphagia, plus nausea), 10 patients were excluded due to red flags. ${ }^{34}$

\section{Diagnostic process}

The diagnostic process for the total group $(\mathrm{N}=810)$ is presented in Table 1 . Most patients were referred 4 weeks to $<6$ months after an accident ( $n=651 ; 80.4 \%$ ), having undergone extensive prior diagnostics and treatment, including medical imaging neck diagnostics $(n=178$; $22.0 \%$ ), cervical soft neck collar ( $\mathrm{n}=514 ; 63.4 \%$ ), pain medication ( $\mathrm{n}=369 ; 45.6 \%)$, and (manual) physiotherapy $(\mathrm{n}=332 ; 40.0 \%)$. A cervical collar was worn for an average of 3.9 weeks $(\mathrm{SD}=2.0)$. The most commonly applied prior therapeutic modalities were manual therapy (mobilization and manipulation) $(\mathrm{n}=234 ; 70.1 \%)$ and massage therapy $(\mathrm{n}=210 ; 63.3)$, and the least applied modalities were active exercise therapy $(n=194 ; 58.4 \%)$ and coaching and education ( $\mathrm{n}=20 ; 6.0 \%$ ). In addition to neck pain, a number of complaints were reported in a substantial proportion of patients ( $\mathrm{n}=804 ; 99.3 \%$; $\geq 3$ complaints: dizziness, headache, 


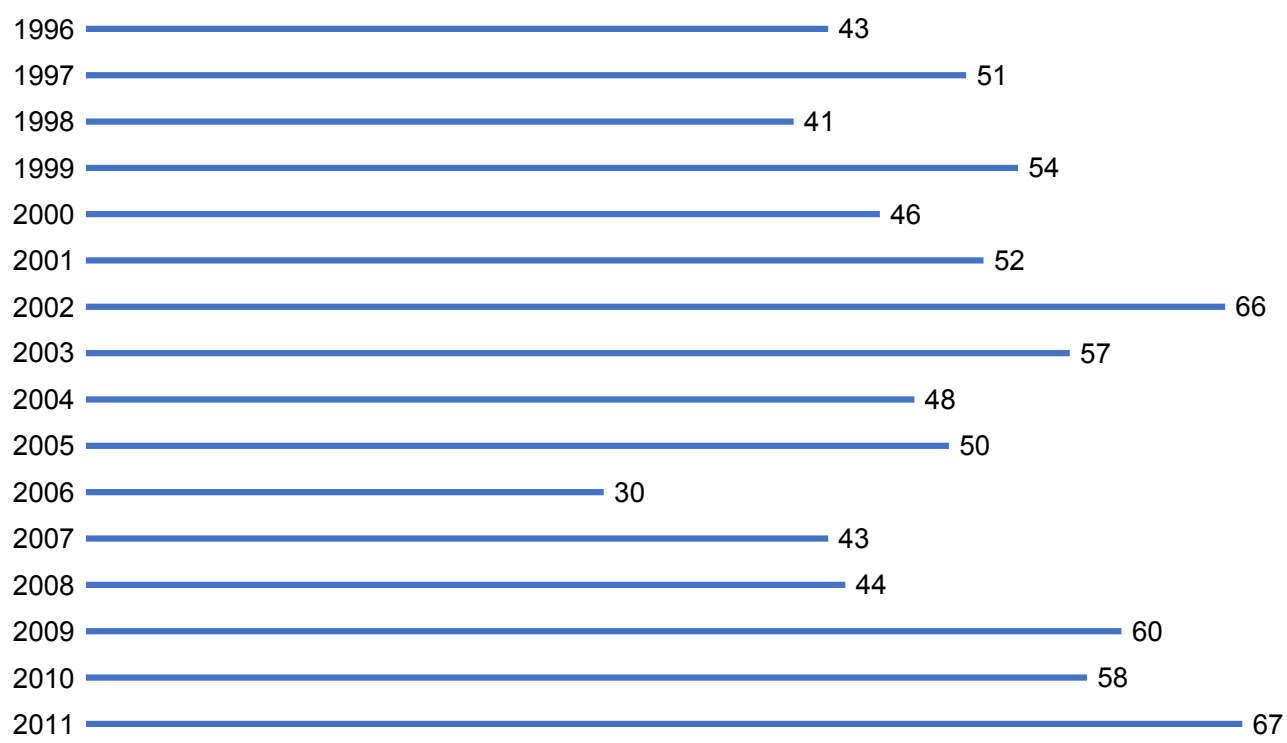

Figure 2 Number of referrals per year 1996-20II ( $\mathrm{N}=810)$.

tinnitus, and cognitive impairments). Most patients were classified as WAD $2(\mathrm{n}=555 ; 68.5 \%)$ with a delayed recovery rate $(n=441 ; 54.4 \%)$. A number of potentially negative indicators for recovery were reported, including observation of pain behavior ( $\mathrm{n}=577$; 92.9\%), $>3$ Waddell's (modified Sobel's) signs ( $\mathrm{n}=530 ; 92.2 \%)$, use of passive coping $(n=443 ; 54.7 \%)$, and fear avoidance $(n=467 ; 57.7 \%)$. Somewhat more than half of all patients were classified as Health Profile C $(n=441 ; 54.4 \%)$ (delayed recovery, high intensity pain, increasing pain, decreasing activities). The diagnostic process of Group A 1996-2002 $(\mathrm{n}=353)$ compared with Group B 2003-2011 $(\mathrm{n}=457)$ is presented in Table 1.

Accident-related characteristics, previous diagnostics and treatment, and current health status and recovery rates differed significantly $(P \leq 0.05)$ between the groups. However, there was no significant difference between the groups in terms of sociodemographic characteristics and preexistent health status. All patients in both groups underwent musculoskeletal examination. The frequency of neurological examinations was not significantly different between the groups. Conversely, the frequency of the otoneurological and psychological examinations differed significantly between groups, occurring more frequently in Group B. Some potential prognostic factors for recovery were significantly less favorable $(P \leq 0.05)$ in Group B (longer period since accident, more serious functioning problems, longer delay in recovery, greater number and variety of complaints, more passive coping, more fear avoidance, and greater likelihood of classification in health profile C). However, other potential prognostic factors for recovery were significantly $(P \leq 0.05)$ more favorable in Group B (fewer medical imaging diagnostics, less use of and shorter time in cervical soft collar, and less pain medication). The overall prognostic factors for recovery were significantly less favorable for Group B. Furthermore, the indication "physiotherapy" differed significantly $(P \leq 0.05)$ between Group A $(\mathrm{n}=353$; $100 \%)$ and Group B $(\mathrm{n}=398 ; 87.1 \%)$.

\section{Therapeutic process}

The therapeutic process for the total group $(\mathrm{N}=810)$ is presented in Table 2. The treatment goals in $529(65.3 \%)$ patients agreed with prognostic health profiles and time Phases I-VI since an accident. Physiotherapy modalities agreed with treatment goals and best available evidence in 442 (83.6\%) of 529 patients. Treatment duration was $\geq 4$ months in 530 (65.4\%) patients and the number of treatment sessions was $\geq 16$ in $469(57.9 \%)$ patients.

The therapeutic process in Group A 1996-2002 $(\mathrm{n}=353)$ compared with Group B 2003-2011 ( $\mathrm{n}=457)$ is presented in Table 2. The treatment goals for all phases (except Phases I, IIIa, and IVa; no statistics when $\mathrm{n}<20$ per phase) differed significantly $(P \leq 0.05)$ between the groups, and more closely agreed in Group B with the prognostic health profile and time Phases I-VI since an accident. Group B also showed significantly closer agreement $(P \leq 0.05)$ between the application of physiotherapy modalities and treatment goals and best available treatment evidence. For instance, we noted a significant shift $(P \leq 0.05)$ toward evidence-based (combinations of) physiotherapy modalities in Group B, including less massage therapy (Group B $17.6 \%$ vs Group A $60.9 \%$ ) and more cognitive and physical principle-based exercise therapy (Group B 91.2\% vs Group A 35.6\%). 
Table I Diagnostic process: differences between Group A 1996-2002 $(n=353)$ and Group B 2003-20II $(n=457)$ regarding the clinical reasoning process in patients with Whiplash-associated disorders (WAD)

\begin{tabular}{|c|c|c|c|c|}
\hline \multirow[t]{2}{*}{$\begin{array}{l}\text { Steps of diagnostic clinical } \\
\text { reasoning process I-V }\end{array}$} & $\begin{array}{l}\text { Total } \\
\mathbf{N}=\mathbf{8} \mathbf{1 0}\end{array}$ & $\begin{array}{l}\text { Group A } \\
1996-2002 \\
n=353\end{array}$ & $\begin{array}{l}\text { Group B } \\
2003-20 \text { I I } \\
n=457\end{array}$ & Difference \\
\hline & n (\%) & n (\%) & n (\%) & aP $\leq 0.05 / \mathrm{NS} /-$ \\
\hline \multicolumn{5}{|l|}{ I. Administration - referral } \\
\hline General physician & $549(67.8)$ & $262(74.2)$ & $287(62.8)$ & a \\
\hline Medical specialist & $164(20.2)$ & $91(25.8)$ & $73(16.0)$ & \\
\hline Self-referral (since 2005) & $97(12.0)$ & - & $97(21.2)$ & \\
\hline \multicolumn{5}{|l|}{ II. History taking } \\
\hline \multicolumn{5}{|l|}{ Sociodemographic characteristics } \\
\hline Age (years) (mean, SD) & $43.0(12.6)$ & $43.0(11.6)$ & $43.2(13.4)$ & NS \\
\hline Gender (female) & $586(72.3)$ & $244(69.1)$ & $342(74.8)$ & NS \\
\hline Educational level (low) & $450(55.6)$ & $192(54.3)$ & $258(56.5)$ & NS \\
\hline Employment status (yes) & $510(62.0)$ & $280(79.3)$ & $230(50.6)$ & NS \\
\hline \multicolumn{5}{|l|}{ Accident characteristics } \\
\hline Direction of impact (back) & $512(63.2)$ & $267(75.6)$ & $248(54.2)$ & a \\
\hline Anticipated collision (no) & $583(72.0)$ & $222(62.9)$ & $361(79.0)$ & a \\
\hline Type of trauma & & & & a \\
\hline Neck trauma without head trauma & $572(70.6)$ & $275(77.9)$ & $297(65.0)$ & \\
\hline Neck trauma with head trauma & $198(24.4)$ & $74(21.0)$ & $124(27.1)$ & \\
\hline Other trauma & $40(4.9)$ & $4(1.1)$ & $36(7.9)$ & \\
\hline Unknown & - & - & - & \\
\hline Time of onset Whiplash-related complaints & & & & a \\
\hline Immediately & $145(17.9)$ & $43(12.2)$ & $102(22.3)$ & \\
\hline$\leq 2$ days & $556(68.9)$ & $279(79.0)$ & $277(60.6)$ & \\
\hline 3-7 days & $109(13.5)$ & $31(8.8)$ & $78(7.9)$ & \\
\hline$>$ I week & - & - & - & \\
\hline \multicolumn{5}{|l|}{ Preexistent health status } \\
\hline \multicolumn{5}{|l|}{ Functioning problems } \\
\hline Activity limitation (yes) & $125(15.4)$ & $40(11.3)$ & $85(18.6)$ & a \\
\hline Participation problems (yes) & $109(13.5)$ & $40(11.3)$ & $69(15.1)$ & NS \\
\hline Job-related problems (yes) & $93(11.5)$ & $36(10.2)$ & $57(12.5)$ & NS \\
\hline Relevant medication use (yes) & $107(13.2)$ & $39(11.0)$ & $68(14.9)$ & NS \\
\hline Previous history of neck injury (yes) & $81(10.0)$ & $33(9.3)$ & $48(10.5)$ & NS \\
\hline Previous neck pain and stiffness (yes) & $144(17.8)$ & $58(16.4)$ & $86(18.8)$ & NS \\
\hline Pain else (yes) & $150(15.8)$ & $44(12.5)$ & $106(23.2)$ & a \\
\hline \multicolumn{5}{|l|}{ Previous diagnostics and treatment } \\
\hline Medical imaging neck diagnostics (yes) & $178(22.0)$ & $96(27.2)$ & $82(17.9)$ & a \\
\hline Cervical soft collar (yes) & $514(63.4)$ & $256(72.5)$ & $258(56.5)$ & a \\
\hline Weeks (mean, SD) & $3.9(2.0)$ & $4.2(2.4)$ & $3.7(1.6)$ & a \\
\hline Pain medication (yes) & $369(45.6)$ & $190(53.8)$ & $179(39.2)$ & a \\
\hline (Manual) physiotherapy (yes) & $332(40.0)$ & $174(49.3)$ & $158(34.6)$ & a \\
\hline \multicolumn{5}{|l|}{ Current health status and recovery rate } \\
\hline \multicolumn{5}{|l|}{ Functioning problems } \\
\hline Impairments in musculoskeletal neck functions (yes) & $810(100)$ & $353(100)$ & $457(100)$ & - \\
\hline Activity limitation (yes) & $688(84.9)$ & $273(77.3)$ & $415(90.8)$ & a \\
\hline Participation problems (yes) & $712(87.9)$ & $288(8 \mid .6)$ & $424(92.8)$ & a \\
\hline Job-related problems (yes) & $312(38.5)$ & $198(84.4)$ & II 4 (24.9) & a \\
\hline
\end{tabular}

(Continued) 
Table I (Continued)

\begin{tabular}{|c|c|c|c|c|}
\hline \multirow[t]{2}{*}{$\begin{array}{l}\text { Steps of diagnostic clinical } \\
\text { reasoning process I-V }\end{array}$} & $\begin{array}{l}\text { Total } \\
\mathbf{N}=\mathbf{8} 10\end{array}$ & $\begin{array}{l}\text { Group A } \\
1996-2002 \\
n=353\end{array}$ & $\begin{array}{l}\text { Group B } \\
2003-201 \text { I } \\
n=457\end{array}$ & Difference \\
\hline & n (\%) & n (\%) & n (\%) & ${ }^{\text {a } P} \leq 0.05 / \mathrm{NS} /-$ \\
\hline Pain medication (yes) & $242(29.9)$ & $138(39.1)$ & $104(22.8)$ & a \\
\hline Type and number of complaints & & & & a \\
\hline$\leq 3:$ neck pain, stiffness, decreased ROM & $6(0.7)$ & $6(1.7)$ & - & \\
\hline 4-6: + dizziness, headache and tinnitus & $374(46.2)$ & $249(70.9)$ & $125(27.4)$ & \\
\hline 7-9: + cognitive impairments & $424(52.3)$ & $96(27.2)$ & $328(71.8)$ & \\
\hline$>9:+$ rest & $6(0.7)$ & $2(0.6)$ & $4(0.9)$ & \\
\hline $\begin{array}{l}\text { Inventory prognostic factors (modified Waddell's sign; } \\
\text { since } 2001 ; n=575)^{b}\end{array}$ & & & & a \\
\hline$\leq 3$ & $45(7.8)$ & $45(38.1)$ & - & \\
\hline$>3$ & $530(92.2)$ & $73(61.9)$ & $457(100)$ & \\
\hline Use of coping & & & & a \\
\hline Active & $329(40.7)$ & $173(49.0)$ & $156(34.1)$ & \\
\hline Inestimable & $38(3.7)$ & $37(10.5)$ & $\mathrm{I}(0.2)$ & \\
\hline Passive & $443(54.7)$ & $143(40.5)$ & $300(65.6)$ & \\
\hline Fear avoidance & & & & a \\
\hline No & $146(18.2)$ & $79(22.4)$ & $67(14.7)$ & \\
\hline Inestimable & $197(24.3)$ & $100(28.3)$ & $97(21.2)$ & \\
\hline Yes & $467(57.7)$ & $174(49.3)$ & $293(64.1)$ & \\
\hline $\begin{array}{l}\text { Presence of signs of central sensitization (since 2009; } \\
n=149 \text { ) }\end{array}$ & & & & - \\
\hline No & $7(4.7)$ & & $7(4.7)$ & \\
\hline Inestimable & $76(51.0)$ & & $76(51.0)$ & \\
\hline Yes & $66(44.3)$ & & $66(44.3)$ & \\
\hline \multicolumn{5}{|l|}{ III. Objectives of examination } \\
\hline Objectives of musculoskeletal examination (yes) & $810(100)$ & $353(100)$ & $457(100)$ & - \\
\hline Objectives of neurological examination (yes) & $136(16.8)$ & $63(17.8)$ & $73(16.0)$ & NS \\
\hline $\begin{array}{l}\text { Objectives of otoneurological examination (since 2000; } \\
n=621 \text { ) (yes/no) }\end{array}$ & $377(60.7) / 244(39.3)$ & $64(39.0) / 100(61.0)$ & $313(68.5) / 144(31.5)$ & a \\
\hline $\begin{array}{l}\text { Objectives of psychological examination (since 2000; } \\
n=621)(\text { yes } / \text { no) }\end{array}$ & 577 (92.9)/44 (7.1) & I33 (8I.I)/3। (I8.9) & $444(97.2) / 13(2.8)$ & a \\
\hline \multicolumn{5}{|l|}{ IV. Clinical examination } \\
\hline Musculoskeletal examination & & & & - \\
\hline Observation of posture (yes) & $810(100)$ & $353(100)$ & $457(100)$ & \\
\hline Active examination of neck function (yes) & $810(100)$ & $353(100)$ & $457(100)$ & \\
\hline Passive examination of neck function (yes) & $810(100)$ & $353(100)$ & $457(100)$ & \\
\hline Palpation of tender points (yes) & $810(100)$ & $353(100)$ & $457(100)$ & \\
\hline \multicolumn{5}{|l|}{ Neurological examination } \\
\hline Sensory testing (yes) & $136(16.8)$ & $63(17.8)$ & $73(16.0)$ & NS \\
\hline Motor testing (yes) & $130(16.0)$ & $63(17.8)$ & $67(14.7)$ & NS \\
\hline Reflex testing (yes) & $130(16.0)$ & $63(17.8)$ & $67(14.7)$ & NS \\
\hline Coordination testing (yes) & $91(11.2)$ & $54(15.3)$ & $37(8.1)$ & a \\
\hline \multicolumn{5}{|l|}{ Otoneurological examination (since $2000 ; \mathrm{n}=62 \mathrm{I}$ ) } \\
\hline Standing tests (yes/no) & $346(55.7) / 275(44.3)$ & $63(38.4) / 101(61.6)$ & $283(61.9) / 174(38.1)$ & a \\
\hline Walking tests (yes/no) & $366(58.9) / 255(4 I .1)$ & $63(38.4) / 101(61.6)$ & $303(66.3) / 154(33.7)$ & a \\
\hline Dizziness tests (yes/no) & $376(60.5) / 245(39.5)$ & $63(38.4) / 101$ (6I.6) & $313(68.5) / 144(31.5)$ & $\mathrm{a}$ \\
\hline Nystagmus tests (yes/no) & $376(60.5) / 245(39.5)$ & $63(38.4) / 101$ (6I.6) & $313(68.5) / 144(31.5)$ & $\mathrm{a}$ \\
\hline
\end{tabular}


Table I (Continued)

\begin{tabular}{|c|c|c|c|c|}
\hline \multirow[t]{2}{*}{$\begin{array}{l}\text { Steps of diagnostic clinical } \\
\text { reasoning process I-V }\end{array}$} & $\begin{array}{l}\text { Total } \\
\mathbf{N}=\mathbf{8} 10\end{array}$ & $\begin{array}{l}\text { Group A } \\
1996-2002 \\
n=353\end{array}$ & $\begin{array}{l}\text { Group B } \\
2003-20 I I \\
n=457\end{array}$ & Difference \\
\hline & n (\%) & n (\%) & n (\%) & ${ }^{\text {a } P} \leq 0.05 / \mathrm{NS} /$ \\
\hline Dix-Hallpike test (yes/no) & $21(3.4) / 600(96.6)$ & $3(1.8) / 161(98.2)$ & $18(3.9) / 439(96.1)$ & NS \\
\hline \multicolumn{5}{|l|}{ Psychological examination } \\
\hline $\begin{array}{l}\text { Observation of pain behavior and fear avoidance } \\
\text { (since 2000; } n=621 \text { ) (yes/no) }\end{array}$ & $577(92.9) / 44(7.1)$ & I33 (8I.I)/3I (I8.9) & $444(97.2) / 13(2.8)$ & a \\
\hline $\begin{array}{l}\text { Use of coping questionnaire (since 2002; } n=523)^{c} \\
\text { (yes/no) }\end{array}$ & $495(94.6) / 28(5.4)$ & $38(57.6) / 28(42.4)$ & $457(100) /-$ & a \\
\hline $\begin{array}{l}\text { Use of fear avoidance questionnaire (since 2002; } \\
n=523)^{c}(\text { yes } / \text { no })\end{array}$ & $495(94.6) / 28(5.4)$ & $38(57.6) / 28(42.4)$ & $457(100) /-$ & $\mathrm{a}$ \\
\hline \multicolumn{5}{|l|}{ V. Analysis and conclusion } \\
\hline Classification WAD & & & & a \\
\hline WAD 0 & - & - & - & \\
\hline WAD I & $123(15.2)$ & $85(24.1)$ & $38(8.3)$ & \\
\hline WAD 2 & $555(68.5)$ & $205(58.1)$ & $350(76.6)$ & \\
\hline WAD 3 & $132(16.3)$ & $63(17.8)$ & $69(15.1)$ & \\
\hline WAD 4 & - & - & - & \\
\hline Time phase since accident & & & & a \\
\hline$>7$ days & $19(2.3)$ & $9(2.5)$ & $10(2.2)$ & \\
\hline I-3 weeks & $140(17.3)$ & $72(20.4)$ & $68(14.9)$ & \\
\hline 4-6 weeks & $192(23.7)$ & $99(28.0)$ & $93(20.4)$ & \\
\hline $7-12$ weeks & $183(22.6)$ & $75(21.2)$ & $108(23.6)$ & \\
\hline $3-6$ months & $155(19.1)$ & $33(9.3)$ & $122(26.7)$ & \\
\hline$>6$ months & $121(14.9)$ & $65(18.4)$ & $56(12.3)$ & \\
\hline Recovery rate since accident & & & & a \\
\hline Normal & - & - & - & \\
\hline Inestimable & $369(45.6)$ & $179(50.7)$ & $190(41.6)$ & \\
\hline Delayed & $44 I(54.4)$ & $174(49.3)$ & $267(58.4)$ & \\
\hline Determination of health profile ${ }^{e}$ & & & & a \\
\hline Profile A & - & - & - & \\
\hline Profile B & $369(45.6)$ & $179(50.7)$ & $190(41.6)$ & \\
\hline Profile C & $44 I(54.4)$ & $174(49.3)$ & $267(58.4)$ & \\
\hline \multicolumn{5}{|l|}{ Prognostic factors related to recovery } \\
\hline $\begin{array}{l}\text { Observation pain behavior (since 2000; } \mathrm{n}=62 \mathrm{I} \text { ) } \\
\text { (yes/no) }\end{array}$ & $577(92.9) / 44(7.1)$ & I33 (8I.I)/3I (I8.9) & $444(97.2) / 13(2.8)$ & $\mathrm{a}$ \\
\hline Modified Waddell's sign $(>3 / \leq 3)^{b}($ since $200 \mathrm{I} ; \mathrm{n}=575)$ & $530(92.2) / 45(7.8)$ & $73(61.9) / 45(38.1)$ & $457(100)$ & a \\
\hline Use of passive coping (yes) & $443(54.7)$ & $143(40.5)$ & - & a \\
\hline Fear avoidance (yes) & $467(57.7)$ & $174(49.3)$ & $300(65.6)$ & a \\
\hline $\begin{array}{l}\text { Presence of signs of central sensitization (since 2009; } \\
\mathrm{n}=149 \text { ) (yes) }\end{array}$ & $47(4 I .5)$ & I8 (23.7) & $293(64.1)$ & $\mathrm{a}$ \\
\hline Indication physiotherapy (yes) & $66(44.3)$ & - & $29(39.7)$ & - \\
\hline
\end{tabular}

Notes: ${ }^{a} P \leq 0.05$; NS, non significant; - , no statistics. ${ }^{b}$ Modified Waddell's signs: tenderness, stimulation, cervical Range of Motion (ROM), regional disturbance, and overreaction. CPsychological questionnaires: Fear Avoidance Beliefs Questionnaire (FABQ) and Pain Coping Inventory (PCl). ${ }^{\circ}$ Classification: WAD 0: no neck symptoms, no physical sign(s); WAD I: neck pain, stiffness or tenderness only, no physical sign(s); WAD 2: neck symptoms and musculoskeletal sign(s); WAD 3: neck symptoms and neurological sign(s); WAD 4: neck symptoms and fracture or dislocation; 'Health Profile: Profile A: normal recovery, low intensity of pain, decreasing pain, increasing activities; Profile B: inestimable recovery, middle intensity of pain, persistent pain, persistent activity limitations; Profile $\mathrm{C}$ : delayed recovery, high intensity of pain, increasing pain, decreasing activities.

\section{Evaluative process}

The evaluative process for the total group $(\mathrm{N}=810)$ and for Groups A $(n=353)$ and B $(n=457)$ is presented in Table 2. The frequency of contacts with physicians in case of unsatisfactory treatment results differed significantly between groups (Group A: $n=67$ [19.0\%] vs Group B: $n=180$ [39.4\%]). The outcome measures pain intensity (VAS), functioning (NDI), and GPE were introduced in 2002. The use of these 


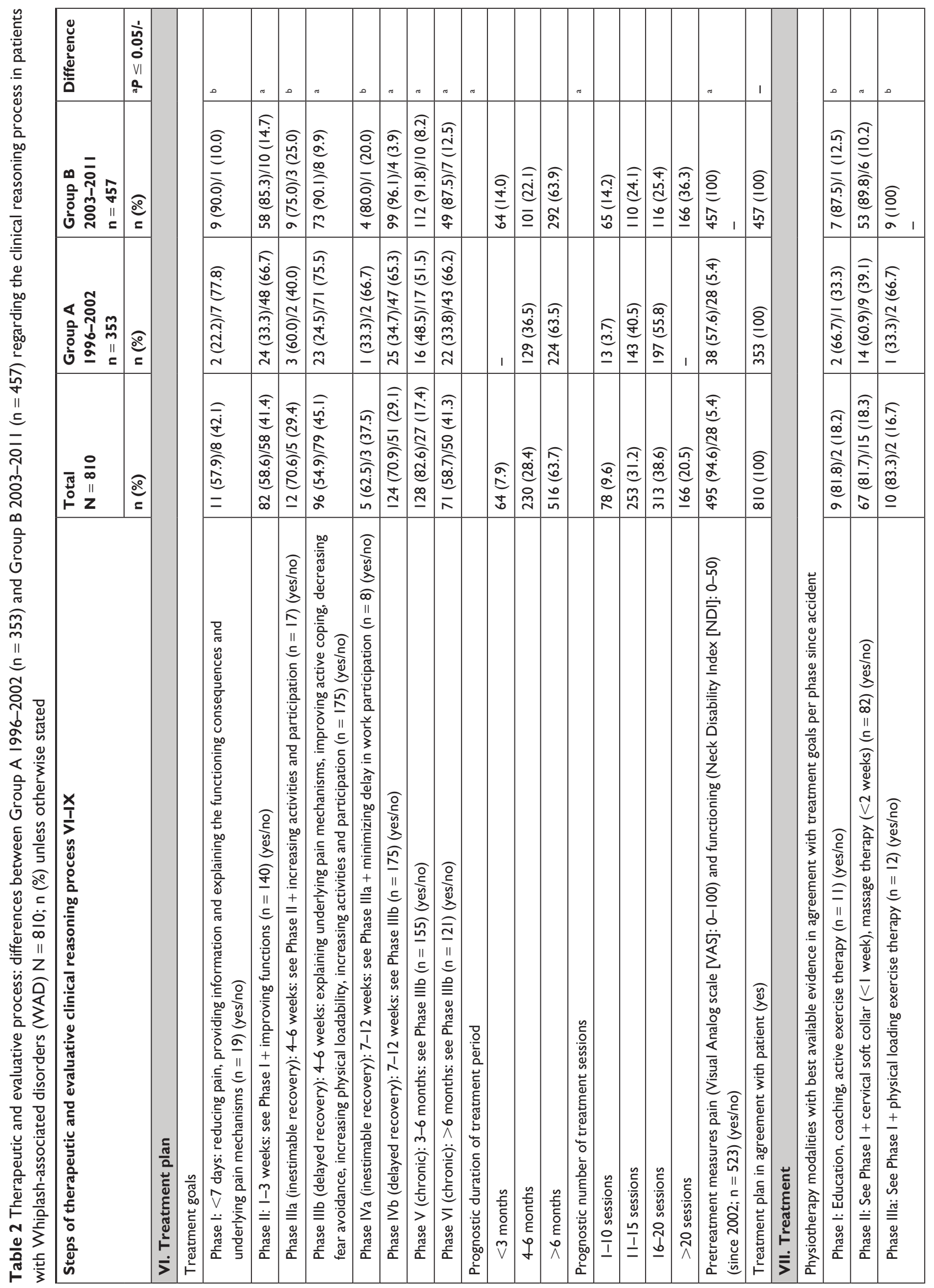




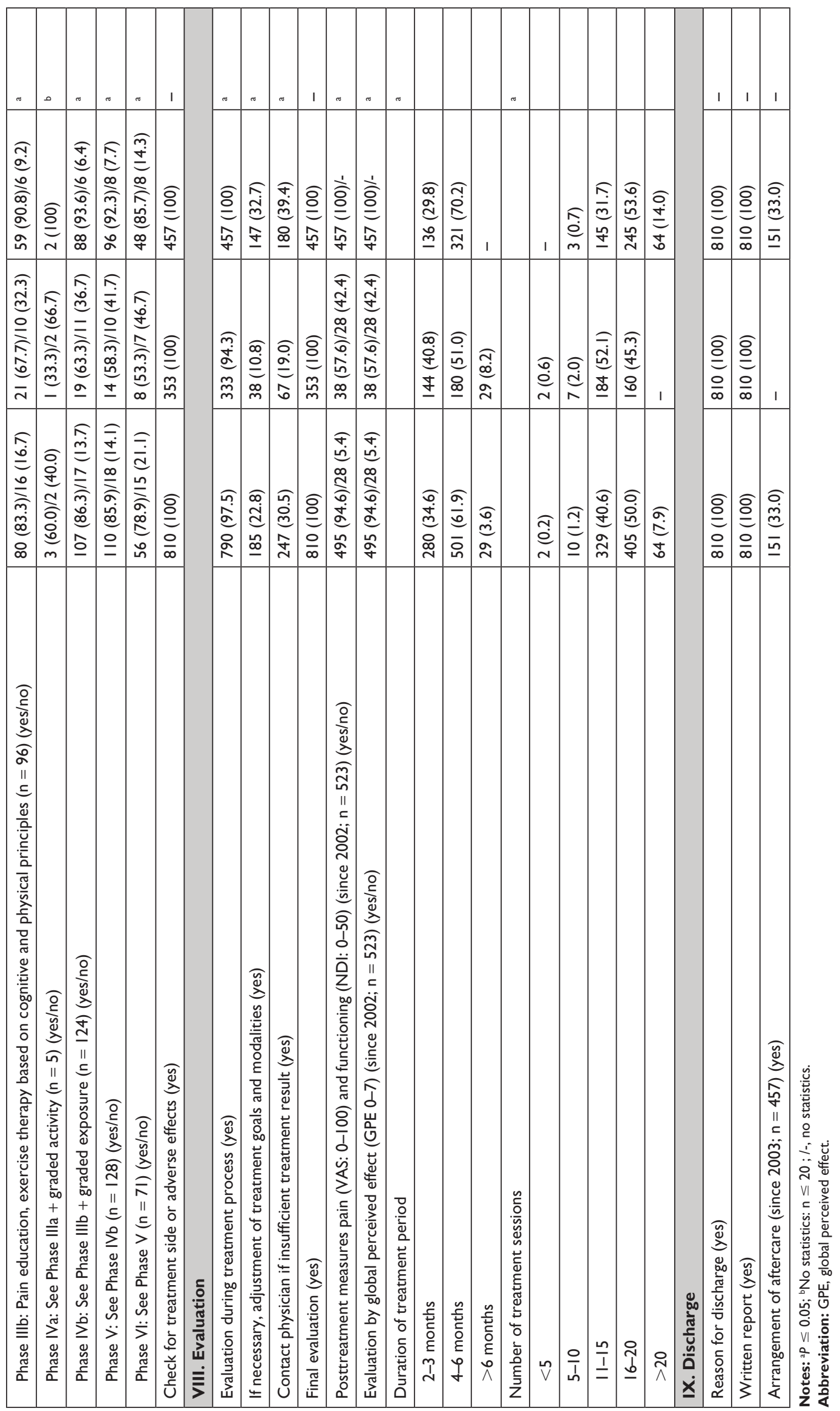


outcome measures differed significantly $(P \leq 0.05)$, in favor of Group B. In addition, the duration of treatment was significantly $(P \leq 0.05)$ shorter and the number of treatment sessions was significantly $(P \leq 0.05)$ greater for Group B. A final discharge report was written for all patients in both groups.

\section{QIs: performance targets}

The mean percentages of the indicator scores per step of the clinical reasoning process and per group were presented in Table 3 .
Twelve indicators $(1,2,3,5,6,8,11,17,21,23,26$, and 27) met performance targets in both periods. Compared with Group A, the mean scores in Group B were significantly higher $(P \leq 0.05)$ for indicators $1,2,5,10,14,15$, and 22, with only indicators 3 and 7 showing higher scores in Group A compared with Group B. Twelve of the 25 indicators (48.0\%) in Group A and 19 of 26 indicators (73.1\%) in Group B met the performance targets of $\geq 80 \%$ or $\leq 30 \%$. The performance targets of two indicators (16 and 28) were nondefined. The difference between the groups, expressed

Table 3 Differences between Group A 1996-2002 $(n=353)$ and Group B 2003-20II ( $n=457)$ expressed as percentages of Qls of the clinical reasoning process and performance target for physiotherapy in patients with Whiplash-associated disorders (WAD)

\begin{tabular}{|c|c|c|c|c|c|}
\hline \multirow[t]{2}{*}{$\begin{array}{l}\text { Steps of clinical peasoning process I-IX } \\
\left.\text { indicators }^{a / b} \text { (level of evidence }{ }^{c}\right)\end{array}$} & $\begin{array}{l}1996-2002 \\
n=353\end{array}$ & $\begin{array}{l}2003-20 I I \\
n=457\end{array}$ & Difference & $\begin{array}{l}1996-2002 \\
n=353\end{array}$ & $\begin{array}{l}2003-20 I I \\
n=457\end{array}$ \\
\hline & $\begin{array}{l}\text { Mean } \\
\text { (SD) }\end{array}$ & $\begin{array}{l}\text { Mean } \\
(\text { SD) }\end{array}$ & $\begin{array}{l}\text { Significance } \\
* P \leq 0.05\end{array}$ & \multicolumn{2}{|c|}{$\begin{array}{l}\text { Performance target } \\
\text { “+” } \geq \mathbf{8 0} \% \text { or } \leq \mathbf{3 0} \%\end{array}$} \\
\hline \multicolumn{6}{|l|}{ I. Administration } \\
\hline Indicator I: patient's information (IV) & $80.6(3.9)$ & $87.0(3.3)$ & $*$ & + & + \\
\hline Indicator 2: patient's request for help (IV) & $82.3(1.5)$ & $87.9(3.6)$ & $*$ & + & + \\
\hline \multicolumn{6}{|l|}{ II. History taking } \\
\hline Indicator 3: sociodemographic characteristics (IV) & $95.7(2.8)$ & $90.4(3.7)$ & * & + & + \\
\hline Indicator 4: accident related information (IV) & $79.0(6.5)$ & $81.1(3.8)$ & & & + \\
\hline Indicator 5: preexistent functioning (IV) & $12.5(4.5)$ & $17.6(4.2)$ & $*$ & + & + \\
\hline Indicator 6: preexistent health status before injury (IV) & II.6 (7.3) & $16.7(4.1)$ & & + & + \\
\hline Indicator 7: previous diagnostics and treatment (IV) & $56.0(15.8)$ & $39.5(4.2)$ & $*$ & & \\
\hline Indicator 8: current health status/functioning in ICF terms (IV) & $100(0.0)$ & $100(0.0)$ & & + & + \\
\hline Indicator 9: recovery since accident and prognostic factors (IV) & $67.4(8.8)$ & $73.2(3.6)$ & & & \\
\hline \multicolumn{6}{|l|}{ III. Objectives of examination } \\
\hline Indicator 10: objectives of examination (IV) & $58.5(4.7)$ & $70.9(4.8)$ & $*$ & & \\
\hline \multicolumn{6}{|l|}{ IV. Clinical examination } \\
\hline Indicator II: musculoskeletal examination (II-IV) & $100(0.0)$ & $100(0.0)$ & & + & + \\
\hline Indicator I2: neurological examination (IV) & $76.3(21.4)$ & $85.3(10.6)$ & & & + \\
\hline $\begin{array}{l}\text { Indicator I3: otoneurological examination (since 2000; number of years: } \\
\mathrm{n}=12 \text { ) (IV) }\end{array}$ & $47.6(30.4)$ & $74.7($ (II.8) & & & \\
\hline $\begin{array}{l}\text { Indicator I4: psychological examination: observation (since } 2000 \text {; } \\
\text { number of years: } n=3 \text { ), questionnaires (since 2003; number of years: } \\
n=9)(I I-I V)\end{array}$ & $45.4(11.7)$ & $99.8(0.6)$ & $*$ & & + \\
\hline \multicolumn{6}{|l|}{ V. Analysis and conclusion } \\
\hline Indicator 15: analysis and conclusion of diagnostic process (II-IV) & $55.7(7.3)$ & $83.3(2.4)$ & $*$ & & + \\
\hline $\begin{array}{l}\text { Indicator 16: presence of central sensitization (since 2009; number of } \\
\text { years: } n=3)(I V)\end{array}$ & - & $46.5(7.5)$ & & Nondefined & \\
\hline \multicolumn{6}{|l|}{ VI. Treatment plan } \\
\hline Indicator 17: treatment goals (IV) & $86.8(5.6)$ & $90.8(1.9)$ & & + & + \\
\hline Indicator 18: prognostics of treatment period and sessions (IV) & $77.5(7.4)$ & $76.6(15.9)$ & & & \\
\hline $\begin{array}{l}\text { Indicator 19: pretreatment scores pain (VAS) and functioning (NDI) } \\
\text { (since 2003; number of years: } n=9 \text { ) (I) }\end{array}$ & - & $100(0.0)$ & & & + \\
\hline \multicolumn{6}{|l|}{ VII. Treatment } \\
\hline Indicator 20: (manual) physiotherapy modalities (II-IV) & $65.2(13.9)$ & $72.3(5.0)$ & & & \\
\hline Indicator 2I: side effects (IV) & $100(0.0)$ & $100(0.0)$ & & + & + \\
\hline
\end{tabular}

(Continued) 
Table 3 (Continued)

\begin{tabular}{|c|c|c|c|c|c|}
\hline \multirow[t]{2}{*}{$\begin{array}{l}\text { Steps of clinical reasoning process I-IX } \\
\text { indicators }^{\mathrm{a} / \mathrm{b}} \text { (level of evidence }{ }^{\mathrm{c}} \text { ) }\end{array}$} & $\begin{array}{l}1996-2002 \\
n=353\end{array}$ & $\begin{array}{l}2003-2011 \\
n=457\end{array}$ & Difference & $\begin{array}{l}1996-2002 \\
n=353\end{array}$ & $\begin{array}{l}2003-2011 \\
n=457\end{array}$ \\
\hline & $\begin{array}{l}\text { Mean } \\
\text { SD }\end{array}$ & $\begin{array}{l}\text { Mean } \\
\text { SD }\end{array}$ & $\begin{array}{l}\text { Significance } \\
* P \leq \mathbf{0 . 0 5}\end{array}$ & \multicolumn{2}{|c|}{$\begin{array}{l}\text { Performance target } \\
\text { "+" } \geq \mathbf{8 0} \% \text { or } \leq \mathbf{3 0} \%\end{array}$} \\
\hline \multicolumn{6}{|l|}{ VIII. Evaluation } \\
\hline Indicator 22: evaluation during treatment (IV) & $71.3(6.9)$ & $79.7(4.3)$ & $*$ & & \\
\hline Indicator 23: subjective end evaluation treatment goals (IV) & $91.7(2.7)$ & $90.8(5.9)$ & & + & + \\
\hline $\begin{array}{l}\text { Indicator 24: objective end evaluation posttreatment pain (VAS) and } \\
\text { functioning (NDI) (2002; number of years: } n=I \text {; since 2003; number } \\
\text { of years: } n=9 \text { ) (I) }\end{array}$ & 57.6 & $98.7(3.9)$ & & & + \\
\hline $\begin{array}{l}\text { Indicator 25: global perceived effect (2002; number of years: } n=I \text {; } \\
\text { since 2003; number of years: } n=9 \text { ) (II) }\end{array}$ & 57.6 & $100(0.0)$ & & & + \\
\hline $\begin{array}{l}\text { Indicator 26: duration treatment period and number treatment } \\
\text { sessions (IV) }\end{array}$ & $100(0.0)$ & $100(0.0)$ & & + & + \\
\hline \multicolumn{6}{|l|}{ IX. Discharge } \\
\hline Indicator 27: final report of discharge (IV) & $100(0.0)$ & $100(0.0)$ & & + & + \\
\hline Indicator 28: after care (since 2003; number of years: $n=9$ ) (IV) & - & $32.4(11.0)$ & & \multicolumn{2}{|l|}{ Nondefined } \\
\hline
\end{tabular}

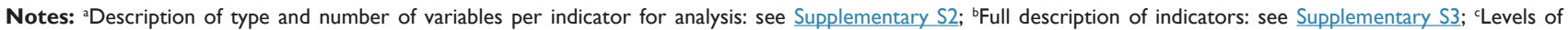
evidence: $I=$ systematic review or $>2$ high-quality controlled trials or high-quality diagnostic studies or high-quality psychometric studies; II = two high-quality controlled trials or high-quality diagnostic studies or high-quality psychometric studies; III = high-quality noncontrolled trials or low-quality diagnostic studies or low-quality psychometric studies; IV = experts opinion and professional consensus or standard.

Abbreviations: NDI, Neck Disability Index; VAS, Visual Analog Scale; QI, quality indicator; ICF, International Classification of Functioning, Disability, and Health.

as number of target indicators met, significantly favored Group B $(P \leq 0.05)$.

\section{Discussion}

In this study, we first systematically developed a novel set of QIs that reflect the clinical reasoning process used in primary care physiotherapy for patients with WAD. In the only study of its type, we then used these QIs to track trends in the quality of primary care physiotherapy of WAD patients over an extended period (16 years; 1996-2011). This analysis was made possible by patient data systematically gathered in a routine setting using a high-quality patient record regularly updated in accordance with the latest guidelines and recommendations. Having defined the quality of physiotherapy care as the degree to which patients were subjected to a methodically performed clinical reasoning process, our analysis suggests that the quality of care improved following the adoption of the Dutch CPG Physiotherapy Management and WAD in 2002. ${ }^{2,3}$ In addition, fewer QIs met performance targets in the period 1996-2002 compared with the period 2003-2011.

During the development of QIs related to the (improvement of) quality of care, we identified a number of studies that described the implementation of $\mathrm{CPGs}^{48-51}$ but no study used a methodology comparable to ours. Similar physiotherapy studies were found $d^{52-57}$ but these studies focused on different patient groups and different scores for quality improvements. ${ }^{58-60}$ International consensus on performance targets and scoring procedures would improve the comparability of studies on the quality of physiotherapy care.

\section{High-quality patient record and the clinical reasoning process}

Due to the absence of a gold standard regarding the quality of the clinical reasoning process, we developed a patient record that described requirements for physiotherapy documentation based on the first draft of the national CPG in $1995,{ }^{24}$ and later updated it based on new CPGs. ${ }^{61}$ Our patient record included a clinical reasoning process algorithm relevant to patients with WAD and is comparable to general instruments such as the Hypothesis-Oriented Algorithm for Clinicians. ${ }^{62,63}$ In our opinion, a well-organized, guideline-based patient record is an indispensable instrument when the goal is quality improvement of the physiotherapy clinical reasoning process in clinical practice.

\section{Set of Qls}

The validity of the QIs was ensured by carefully chosen panels of both experts and users, and the clarity, relevancy, acceptability and feasibility of the QIs received substantial support in terms of face and content validity. Although no other stakeholders were involved in the process of QI development, we accept the varied perspectives of patients, health insurers, policy makers, and other stakeholders. ${ }^{64}$

The levels of evidence established for QIs were largely consistent with the Dutch CPG Neck Pain (including WAD) 
published in $2016^{12}$ and with international CPGs, ${ }^{4-6,9-11}$ with most evidence based on the psychometrics of psychological questionnaires and outcome indicators, while evidence supporting recommendations on diagnosis, prognosis, and treatment was often weak to moderate at best. ${ }^{4-6,-12}$ Establishing a higher level of evidence will require an ongoing effort, drawing on a mixture of scientific research, clinical practice and observation, and based on a multivariable diagnostic and therapeutic approach, with support from multiple stakeholders (including patients). ${ }^{64-66}$

\section{Quality improvement}

Although 12 indicators already met performance targets before 2002, the number of positively assessed indicators for performance targets continued to improve over the period 2003-2011. The most striking quality improvements were seen in the analysis and conclusion of the diagnostic process, and in the frequency of use of outcome measures such as pain intensity, functioning, and GPE. However, ceiling effects (indicator $=100 \%)$ were noted for five indicators $(8,11,21$, 26 , and 27), suggesting that critical assessment of these QIs is warranted.

Seven indicators $(7,9,10,13,18,20$, and 22) failed to meet performance targets in either period. Earlier findings also suggested that indicators including previous diagnostics and treatment, objectives of examination, treatment plan, and treatment and evaluation represent the weakest links in the clinical reasoning and decision-making process. ${ }^{67}$ Nevertheless, in both periods the mean scores for most indicators were $\geq 70 \%$ and thus sufficient, suggesting that participating physiotherapists were already applying recommended management approaches, resulting in a limited improvement on some of the QIs. This explanation corresponds to the findings of another implementation study in which a tailored, multivariate guideline implementation was compared with usual practice. ${ }^{68}$ In that study, it appeared that usual care was broadly in line with recommendations even before implementation. ${ }^{68}$ The future development, implementation, and evaluation of QIs should elaborate on the findings of these studies.

\section{$R C D$ vs randomized controlled trial (RCT)}

The data on WAD patients in this study were collected routinely over a period of 16 years, in a large population, and without narrow inclusion and exclusion criteria, under routine care conditions that differ from the artificial conditions of a RCT. To the best of our knowledge, there are currently no other examples of the use of RCD in the (manual) physiotherapy management of WAD patients.
RCD offer several advantages. Data collection under real-life practice conditions maximizes representativeness and generalizability, minimizes costs and effort, and allows the capture of information from large populations and many clinical practices over long periods. However, these advantages should be viewed with caution as errors and biases due to incomplete registration can interfere with results. ${ }^{22}$ To use RCD properly, some challenges may have to be overcome. ${ }^{69}$ Consequently, in order to assess the quality of our findings, we compared our data to the criteria of the Reporting of Studies Conducted using Observational Routinely collected Data statement and found that most criteria were met. ${ }^{70}$

The use of RCD generally represents a useful alternative for understanding the quality of physiotherapy care as many evidentiary gaps currently exist concerning prognostics, diagnostics, and treatment in patients with WAD. RCD on physiotherapy management in patients with different phases of WAD may provide a more complete view of the clinical reasoning process and a more comprehensive and realistic view of routine practice than data gathered during an RCT. In the majority of RCTs $(n=122)$ involving patients with nonspecific neck pain, the clinical reasoning process was reportedly incomplete, specifically in the diagnostic aspect of the process, with only $6 \%$ of the RCTs including a complete diagnostic process. ${ }^{71}$

Compared with RCTs, there is little empirical guidance on the interpretation of RCD evidence. We need to develop tools for assessment of bias risk, generalizability, and data validity and to discuss the limitations of RCTs and whether these limitations can be best overcome through optimal use of RCD. Despite these limitations, we expect that the RCD underlying this study could plausibly act as preliminary evidence concerning (manual) physiotherapy management and WAD and could be used to improve the design of future RCTs. In conclusion, while improvement of RCT quality is an important goal, broadening our focus to include improved, accurate documentation of patient records is also worth considering.

\section{A shifting diagnostic process: patient characteristics and prognostic factors}

Many characteristics and prognostic factors have shifted in the direction of chronicity (and delayed recovery). Internationally, the proportion of patients with chronic WAD is now around $20 \%-40 \%{ }^{72}$ The increase in the proportion of patients with chronic WAD in Group B reflects an increase in the number of patients with multiple complaints $(>7)$, more unfavorable prognostic factors (Waddell's sign $>3$ ), greater use of passive 
coping, and more fear avoidance. This shift conflicts with one of the primary goals of patient management in primary care, namely prevention of WAD chronicity.

However, although notes in early records were based on the clinical observation of pain behavior, coping and fear avoidance, and on an inventory of symptoms of central sensitization during the process of history taking, a gradual shift has taken place toward the application of validated psychological questionnaires (coping: Pain Coping Inventory ${ }^{73}$ and fear avoidance: Fear Avoidance Beliefs Questionnaire). ${ }^{74}$

A systematic use of psychological questionnaires, including psychological factors prognostic for recovery, ${ }^{75,76}$ was introduced as a component of patient records in 2002 and symptoms related to central sensitization were added in 2009 .

Based on the gradual improvement in the evidence supporting prognostic factors for WAD, a further update of patient records should now be considered, with greater emphasis on initial pain during anamnesis; postinjury psychological factors, such as coping, mood, and fear of movement; and pain (especially chronic pain) associated with a hypervigilant nervous system. ${ }^{77-80}$ Better understanding and skills in the application and interpretation of measurement instruments will allow physiotherapists to assess these factors earlier in the process of care and will aid development of an adequate therapeutic intervention. However, these new features of patient records will require active implementation strategies, particularly in history taking, clinical assessment, and individual interpretation of the questionnaire score, before visible changes and quality improvements can be expected.

\section{A shifting therapeutic process: treatment plan and treatment}

Following changes in treatment goals as a function of the time since an accident, physiotherapy modalities have shifted in the direction of evidence- and guideline-based treatment (see Supplementary S1). In the current study, we noted relatively large changes in the use of physiotherapy modalities in Group B, which presumably indicates broader implementation of guideline-based interventions. For example, massage therapy was the most frequently applied intervention (70\%) in the period 1996-2002, but this intervention declined to around $40 \%$ in the period 2003-2011. By contrast, the use of (cognitive and physical) active exercise therapy has increased from $35 \%$ in the period 1996-2002 to $90 \%$ in the period 2003-2011.

At the present time, the physiotherapy modalities active exercise therapy, patient coaching, and pain education, in combination with pain medication and manual therapy, are the recommended primary interventions for patients at different stages of Whiplash injury. The positive effect of these physiotherapy modalities (or combinations of) compared to placebo or other treatment is supported by low-tomoderate levels of evidence. , $^{9,-90}$

\section{A shifting evaluative process}

Treatment effects were evaluated by interviewing patients both during and after completion of treatment, and this approach was consistently applied during the entire study period. However, the proportion of patients with chronic WAD increased substantially in the period 2003-2011. Consequently, contacts with physicians were more frequent, the duration of treatment was between 4 and 6 months for most patients, and the number of treatment sessions increased ( $>16$ sessions). The recently published Dutch CPG Neck pain (including WAD) advises only three sessions for patients with profile A (normal recovery, low intensity of pain, decreasing pain, and increasing activities), with no advice regarding other profiles. ${ }^{12}$ As the average number of sessions noted in this study differs markedly from the number covered by health insurance in the Netherlands, a gap clearly exists between clinical practice and health insurance policy.

The use of recommended and validated questionnaires (VAS, NDI, and GPE) to provide an objective evaluation at the end of treatment began in 2003 and remains in line with current CPG recommendations on physiotherapy management and WAD. ${ }^{12}$ The frequency of use of these questionnaires was presented as a process indicator rather than as an outcome indicator. An evaluation of the scores of these questionnaires as an outcome indicator will be presented in manuscript in preparation.

\section{Limitations}

The principal limitation of this retrospective cohort study was that it was conducted in only two primary care physiotherapy practices in the Netherlands and included data collected by eight physiotherapists in total. Although the characteristics of the participating physiotherapists were comparable to the national average ${ }^{91}$ and the patient sample was comparable to participants in another Dutch study, ${ }^{92}$ the number of participating practices and physiotherapists may have limited generalizability and thus reduced the external validity of the results. A major concern for future studies should be recruitment of a greater number of participating practices and physiotherapists, thus substantially enhancing generalizability and the ability to investigate the psychometrics of the set of QIs. 
Another limitation was that although this study took international literature and CPGs into account, it was conducted within the framework of Dutch primary care physiotherapy and specifically within the established framework for patients with WAD. This implies that the results may be more relevant to the Dutch situation and perhaps less applicable internationally. Nevertheless, although national in scope, many of the lessons learned will surely resonate with an international audience.

\section{Conclusion}

Bearing in mind the goals of this study, its limitations, and the possibly limited external validity of the results, we cautiously conclude that 1) the systematic development of a preliminary set of QIs is a valid approach; 2) RCD can provide valuable information on trends and improvements in the quality of primary physiotherapy care; and 3) the quality of physiotherapy management of patients with WAD met the predetermined performance targets based on the preliminary set of QIs.

\section{Author contributions}

All authors contributed to data analysis, drafting and revising the article, gave final approval of the version to be published, and agree to be accountable for all aspects of the work.

\section{Disclosure}

The authors report no conflicts of interest in this work.

\section{References}

1. Spitzer WO, Skovron ML, Salmi LR, et al. Scientific monograph of the Quebec Task Force on Whiplash-associated disorders: redefining "whiplash" and its management. Spine. 1995;20(8 Suppl):1S-73S.

2. Bekkering GE, Hendriks HJM, Lanser K, et al. KNGF-richtlijn Whiplash. Ned Tijdschr Fysiother. 2001;111(3 supplement):S1-S25.

3. Scholten-Peeters GG, Bekkering GE, Verhagen AP, et al. Clinical practice guideline for the physiotherapy of patients with whiplash-associated disorders. Spine. 2002;27(4):412-422.

4. Leigh TA. Best Practices Task Force. Clinical Practice Guidelines for the Physiotherapy Treatment of Whiplash-Associated Disorders. Vancouver, BC: Physiotherapy Association British Columbia; 2004.

5. Moore A, Jackson A, Jordan J, et al. Clinical Guidelines for the Physiotherapy Management of Whiplash-Associated Disorder (WAD). London: Chartered Society of Physiotherapy; 2005.

6. TRACsa. Clinical Guidelines for Best Practice Management of Aacute and Chronic Whiplash Associated Disorders: Clinical Resource Guide. Adelaide: South Australian Centre for Trauma and Injury Recovery; 2008.

7. Hurwitz EL, Carragee EJ, van der Velde G, et al. Bone and Joint Decade 2000-2010 Task Force on Neck Pain and Its Associated Disorders. Treatment of neck pain: noninvasive interventions: results of the Bone and Joint Decade 2000-2010 Task Force on Neck Pain and Its Associated Disorders. Spine. 2008;33(4 Suppl):S123-S152.

8. Carroll LJ, Holm LW, Hogg-Johnson S, et al. Course and prognostic factors for neck pain in whiplash-associated disorders (WAD): results of the Bone and Joint Decade 2000-2010 Task Force on Neck Pain and Its Associated Disorders. J Manipulative Physiol Ther. 2009;32(2 Suppl): S97-S107.
9. Sterling M. Physiotherapy management of whiplash-associated disorders (WAD). J Physiother. 2014;60(1):5-12.

10. Côté P, Wong JJ, Sutton D, et al. Management of neck pain and associated disorders: a clinical practice guideline from the Ontario Protocol for Traffic Injury Management (OPTIMa) Collaboration. Eur Spine J. 2016;25(7):2000-2022.

11. Bussières AE, Stewart G, Al-Zoubi F, et al. The treatment of neck pain-associated disorders and Whiplash-associated disorders: a clinical practice guideline. J Manipulative Physiol Ther. 2016;39(8): 523-564.

12. Bier JD, Scholten-Peeters GGM, Staal JB, et al. KNGF-Richtlijn Nekpijn. Amersfoort: Koninklijk Nederlands Genootschap voor Fysiotherapie; 2016. Dutch.

13. Farmer AP, Légaré $\mathrm{F}$, Turcot L, et al. Printed educational materials: effects on professional practice and health care outcomes. Cochrane Database Syst Rev. 2008;3(3):CD004398.

14. Rebbeck T, Macedo LG, Maher CG. Compliance with clinical guidelines for whiplash improved with a targeted implementation strategy: a prospective cohort study. BMC Health Serv Res. 2013;13(1):213.

15. Jull GA, Söderlund A, Stemper BD, et al. Toward optimal early management after whiplash injury to lessen the rate of transition to chronicity: discussion paper 5. Spine. 2011;36(25 Suppl):S335-S342.

16. Higgs J, Jones MA, Loftus S, Christensen N. Clinical Reasoning in the Health Professions. Edinburgh: Butterworth-Heinemann; 2008: 3-18.

17. Jones MA, Rivett DA. Clinical Reasoning for Manual Therapists. Edinburgh: Butterworth-Heinemann; 2004:1-24.

18. Campbell S, Braspenning J, Hutchinson A, Marshall M. Research methods used in developing and applying quality indicators in primary care. In: Grol R, Baker R, Moss F, editors. Quality Improvement Research: Understanding the Science of Change in Health Care. London: BMJ Publishing Group; 2004:6-28.

19. Lawrence M, Olesen F. Indicators of quality in health care. Eur $J$ Gen Pract. 1997;3(3):103-108.

20. Mainz J. Defining and classifying clinical indicators for quality improvement. Int J Qual Health Care. 2003;15(6):523-530.

21. Hoque DME, Kumari V, Hoque M, Ruseckaite R, Romero L, Evans SM. Impact of clinical registries on quality of patient care and clinical outcomes: a systematic review. PLoS One. 2017;12(9):e0183667.

22. Hemkens LG, Contopoulos-Ioannidis DG, Ioannidis JP. Routinely collected data and comparative effectiveness evidence: promises and limitations. CMAJ. 2016;188(8):E158-E164.

23. Heerkens $Y$, van den Heuvel J, van Klaveren T, van Ravensberg D, van den Heuvel C, van Meeteren N. Classification Allied Health CareVersion Physiotherapy. Amersfoort: Nederlands Paramedisch Instituut; 1995. Dutch.

24. KNGF. Richtlijnen voor de Fysiotherapeutische Verslaglegging. Amersfoort: Koninklijk Nederlands Genootschap voor Fysiotherapie; 1993. Dutch.

25. Brook RH, Mcglynn EA, Shekelle PG. Defining and measuring quality of care: a perspective from US researchers. Int J Qual Health Care. 2000;12(4):281-295.

26. de Kooning M, Daenen L, Cras P, Gidron Y, Roussel N, Nijs J. Autonomic response to pain in patients with chronic whiplash associated disorders. Pain Physician. 2013;16(3):E277-E285.

27. de Kooning M, Daenen L, Roussel N, et al. Endogenous pain inhibition is unrelated to autonomic responses in acute whiplash-associated disorders. J Rehabil Res Dev. 2015;52(4):431-440.

28. van Oosterwijck J, Nijs J, Meeus M, Paul L. Evidence for central sensitization in chronic whiplash: a systematic literature review. Eur $J$ Pain. 2013;17(3):299-312.

29. Meeus M, Nijs J, Hamers V, Ickmans K, Oosterwijck J. The efficacy of patient education in whiplash associated disorders: a systematic review. Pain Physician. 2012;15(5):351-361.

30. Nijs J, van Houdenhove B, Oostendorp RA. Recognition of central sensitization in patients with musculoskeletal pain: application of pain neurophysiology in manual therapy practice. Man Ther. 2010;15(2): $135-141$. 
31. Nordin M, Carragee EJ, Hogg-Johnson S, et al. Bone and Joint Decade 2000-2010 Task Force on Neck Pain and Its Associated Disorders. Assessment of neck pain and its associated disorders: results of the Bone and Joint Decade 2000-2010 Task Force on Neck Pain and Its Associated Disorders. Spine. 2008;33(4s):S110-S122.

32. Dutton M. Orthopedic Examination, Evaluation and Intervention. New York: McGraw-Hill Medical Publishing Division; 2004.

33. Gerard JA, Kleinfield ST. Orthopedic Testing. New York: Churchill Livingstone; 1993.

34. Greenhalgh S, Selfe J. RedFlags: A Guide to Identifying Serious Pathology of the Spine. Edinburgh: Churchill Livingstone; 2006.

35. Harms-Ringdal K, Nachemson A. Acute and subacute neck pain: nonsurgical treatment. In: Nachemson AL, Jonsson E, editors. Neck and Back Pain: The Scientific Evidence of Causes, Diagnosis, and Treatment. Philadelphia: Lippincott Williams \& Wilkins; 2000:327-338.

36. van Tulder M, Goossens M, Hoving J. Nonsurgical treatment of chronic neck pain. In: Nachemson AL, Jonsson E, editors. Neck and Back Pain: The Scientific Evidence of Causes, Diagnosis and Treatment. Philadelphia: Lippincott Williams \& Wilkins; 2000:339-354.

37. World Health Organization. International Classification of Functioning, Disability and Health. Geneva: WHO; 2001.

38. Schwarzkopf SR, Ewert T, Dreinhöfer KE, Cieza A, Stucki G. Towards an ICF Core Set for chronic musculoskeletal conditions: commonalities across ICF Core Sets for osteoarthritis, rheumatoid arthritis, osteoporosis, low back pain and chronic widespread pain. Clin Rheumatol. 2008; 27(11):1355-1361.

39. Scholten RJPM, Tuut MK, Kremer LCM, Assendelft WJJ. Beoordelen van de kwaliteit van medisch-wetenschappelijk onderzoek. In: Van Everdingen JJE, Burgers JS, Assendelft WJJ, Swinkels JA, Van Barneveld TA, Van de Klundert JLM, editors. Evidence-Based Richtlijnontwikkeling. Houten: Bohn Stafleu Van Loghum; 2004:158-171. Dutch.

40. Pietrobon R, Coeytaux RR, Carey TS, Richardson WJ, Devellis RF. Standard scales for measurement of functional outcome for cervical pain or dysfunction: a systematic review. Spine. 2002;27(5):515-522.

41. Wewers ME, Lowe NK. A critical review of visual analogue scales in the measurement of clinical phenomena. Res Nurs Health. 1990; 13(4):227-236.

42. Vernon H, Mior S. The Neck Disability Index: a study of reliability and validity. J Manipulative Physiol Ther. 1991;14(7):409-415.

43. Stratford P, Gill C, Westaway M. Assessing disability and change on individual patients: a report of a patient specific measure. Physiotherapy Canada. 1995;47(4):258-263.

44. Pool JJ, Ostelo RW, Hoving JL, Bouter LM, de Vet HC. Minimal clinically important change of the Neck Disability Index and the Numerical Rating Scale for patients with neck pain. Spine. 2007;32(26): 3047-3051.

45. Ostelo RW, de Vet HC. Clinically important outcomes in low back pain. Best Pract Res Clin Rheumatol. 2005;19(4):593-607.

46. Nijs J, van Oosterwijck J, de Hertogh W. Rehabilitation of chronic whiplash: treatment of cervical dysfunctions or chronic pain syndrome? Clin Rheumatol. 2009;28(3):243-251.

47. Walton DM, Pretty J, Macdermid JC, Teasell RW. Risk factors for persistent problems following whiplash injury: results of a systematic review and meta-analysis. J Orthop Sports Phys Ther. 2009;39(5):334-350.

48. Rebbeck T, Maher CG, Refshauge KM. Evaluating two implementation strategies for whiplash guidelines in physiotherapy: a cluster randomised trial. Aust J Physiother. 2006;52(3):165-174.

49. van der Wees PJ, Jamtvedt G, Rebbeck T, de Bie RA, Dekker J, Hendriks EJ. Multifaceted strategies may increase implementation of physiotherapy clinical guidelines: a systematic review. Aust J Physiother. 2008;54(4):233-241.

50. Rebbeck T, Macedo LG, Maher CG. Compliance with clinical guidelines for whiplash improved with a targeted implementation strategy: a prospective cohort study. BMC Health Serv Res. 2013;13(13):213.

51. Corkery MB, Edgar KL, Smith CE. A survey of physical therapists' clinical practice patterns and adherence to clinical guidelines in the management of patients with whiplash associated disorders (WAD). J Man Manip Ther. 2014;22(2):75-89.
52. Jansen MJ, Hendriks EJ, Oostendorp RA, Dekker J, De Bie RA. Quality indicators indicate good adherence to the clinical practice guideline on "Osteoarthritis of the hip and knee" and few prognostic factors influence outcome indicators: a prospective cohort study. Eur J Phys Rehabil Med. 2010;46(3):337-345.

53. Peter WF, Hurkmans EJ, van der Wees PJ, Hendriks EJ, van Bodegom-Vos L, Vliet Vlieland TP. Healthcare quality indicators for physiotherapy management in hip and knee osteoarthritis and rheumatoid arthritis: a Delphi study. Musculoskeletal Care. 2016; 14(4):219-232.

54. Gijsbers HJ, Lauret GJ, van Hofwegen A, van Dockum TA, Teijink JA, Hendriks HJ. Development of quality indicators for physiotherapy for patients with PAOD in the Netherlands: a Delphi study. Physiotherapy. 2016;102(2):196-201.

55. Rutten GM, Harting J, Bartholomew LK, Schlief A, Oostendorp RA, de Vries NK. Evaluation of the theory-based Quality Improvement in Physical Therapy (QUIP) programme: a one-group, pre-test post-test pilot study. BMC Health Serv Res. 2013;13:194.

56. Nijkrake MJ, Keus SH, Ewalds H, et al. Quality indicators for physiotherapy in Parkinson's disease. Eur J Phys Rehabil Med. 2009; 45(2):239-245.

57. Stelfox HT, Bobranska-Artiuch B, Nathens A, Straus SE. A systematic review of quality indicators for evaluating pediatric trauma care. Crit Care Med. 2010;38(4):1187-1196.

58. Scholte M, Neeleman-van der Steen CW, Hendriks EJ, Nijhuis-van der Sanden MW, Braspenning J. Evaluating quality indicators for physical therapy in primary care. Int J Qual Health Care. 2014;26(3):261-270.

59. Braspenning JCC, Pijnenborg L, Grol RPTM. Ontwikkelen van kwaliteitsindicatoren. In: Braspenning JCC, Pijnenborg L, In 't Veld CJ, Grol RPTM, editors. Werken aan Kwaliteit in de Huisartsenpraktijk. Indicatoren Gebaseerd op de NHG-Standaarden. Houten: Bohn Stafleu Van Loghum; 2005:10-20. Dutch.

60. Pijnenborg L, Bouma M, Braspenning JCC, Witmer H. Toepassen van kwaliteitsindicatoren. In: Braspenning JCC, Pijnenborg L, In 't Veld CJ, Grol RPTM, editors. Werken aan Kwaliteit in de Huisartsenpraktijk. Indicatoren Gebaseerd op de NHG-Standaarden. Houten: Bohn Stafleu Van Loghum; 2005:21-30. Dutch.

61. Heerkens YF, Lakerveld-Heyl K, Verhoeven ALJ, Hendriks HJM. KNGF-richtlijn Fysiotherapeutische Verslaglegging. Ned Tijdschr Fysiother. 2007;117(6):Supplement 1-20. Dutch.

62. Rothstein JM, Echternach JL. Hypothesis-oriented algorithm for clinicians. A method for evaluation and treatment planning. Phys Ther. 1986;66(9):1388-1394.

63. Rothstein JM, Echternach JL, Riddle DL. The Hypothesis-Oriented Algorithm for Clinicians II (HOAC II): a guide for patient management. Phys Ther. 2003;83(5):455-470.

64. van der Weijden T, Légaré F, Boivin A, et al. How to integrate individual patient values and preferences in clinical practice guidelines? A research protocol. Implement Sci. 2010;5:10.

65. van Trijffel E, Lindeboom R, Bossuyt PM, et al. Indicating spinal joint mobilisations or manipulations in patients with neck or low-back pain: protocol of an inter-examiner reliability study among manual therapists. Chiropr Man Therap. 2014;22:22.

66. Jones MA, Jensen G, Edwards I. Clinical reasoning in physiotherapy. In: Higgs J, Jones M, Loftus S, Christensen N, editors. Clinical Reasoning in the Health Professions. Edinburgh: Butterworth-Heinemann; 2008:193-204.

67. Oostendorp RA, Rutten GM, Dommerholt J, Nijhuis-van der Sanden MW, Harting J. Guideline-based development and practice test of quality indicators for physiotherapy care in patients with neck pain. J Eval Clin Pract. 2013;19(6):1044-1053.

68. Bernhardsson S, Larsson MEH. Does a tailored guideline implementation strategy have an impact on clinical physiotherapy practice? A nonrandomized controlled study. J Eval Clin Pract. Epub 2018 May 28.

69. Jorm L. Routinely collected data as a strategic resource for research: priorities for methods and workforce. Public Health Res Pract. 2015; 25(4):e2541540. 
70. Benchimol EI, Smeeth L, Guttmann A, et al. The REporting of studies Conducted using Observational Routinely-collected health Data (RECORD) statement. PLoS Med. 2015;12(10):e1001885.

71. Maissan F, Pool J, de Raaij E, Mollema J, Ostelo R, Wittink H. The clinical reasoning process in randomized clinical trials with patients with non-specific neck pain is incomplete: a systematic review. Musculoskelet Sci Pract. 2018;35:8-17.

72. Ioppolo F, Rizzo RS. Epidemiology of whiplash-associated disorders. In: Alpini DC, Brugnoni G, Cesarani A, editors. Whiplash Injuries: Diagnosis and Treatment. Italia: Springer Verlag; 2014:13-16.

73. Kraaimaat FW, Bakker B, Evers AWM. Pijncoping-strategieën bij chronische pijn patiënten: De ontwikkeling van de Pijn-CopingInventarisatielijst (PCI). Gedragstherapie. 1997;3:185-201. Dutch.

74. Waddell G, Newton M, Henderson I, Somerville D, Main CJ. A FearAvoidance Beliefs Questionnaire (FABQ) and the role of fear-avoidance beliefs in chronic low back pain and disability. Pain. 1993;52(2): $157-168$.

75. Vangronsveld KL, Peters M, Goossens M, Vlaeyen J. The influence of fear of movement and pain catastrophizing on daily pain and disability in individuals with acute whiplash injury: a daily diary study. Pain. 2008;139(2):449-457.

76. Campbell L, Smith A, Mcgregor L, Sterling M. Psychological factors and the development of chronic Whiplash-associated disorder(s): a systematic review. Clin J Pain. 2018;34(8):755-768.

77. Bohman T, Côté P, Boyle E, Cassidy JD, Carroll LJ, Skillgate E. Prognosis of patients with whiplash-associated disorders consulting physiotherapy: development of a predictive model for recovery. $B M C$ Musculoskelet Disord. 2012;13:264.

78. Carstensen TB. The influence of psychosocial factors on recovery following acute whiplash trauma. Dan Med J. 2012;59(12):B4560.

79. Carroll LJ, Holm LW, Hogg-Johnson S, et al. Course and prognostic factors for neck pain in whiplash-associated disorders (WAD): results of the Bone and Joint Decade 2000-2010 Task Force on Neck Pain and its associated disorders. Spine. 2008;33(4 Suppl):S83-S92.

80. Kamper SJ, Rebbeck TJ, Maher CG, Mcauley JH, Sterling M. Course and prognostic factors of whiplash: a systematic review and metaanalysis. Pain. 2008;138(3):617-629.
81. Walton DM, Elliott JM. An Integrated Model of Chronic WhiplashAssociated Disorder. J Orthop Sports Phys Ther. 2017;47(7):462-471.

82. Michaleff ZA, Maher CG, Lin CW, et al. Comprehensive physiotherapy exercise programme or advice for chronic whiplash (PROMISE): a pragmatic randomised controlled trial. Lancet. 2014;384(9938):133-141.

83. Meeus M, Nijs J, Hamers V, Ickmans K, Oosterwijck JV. The efficacy of patient education in whiplash associated disorders: a systematic review. Pain Physician. 2012;15(5):351-361

84. van Son M, Zemouri C, Hoving J, Hulshof C, Frings-Dresen M. Update van de Kennis over Whiplash: Diagnose, Prognose, Interventies en Patiëntperspectief. Amsterdam: Coronel Instituut, Universiteit van Amsterdam; 2015. Dutch.

85. Gross A, Langevin P, Burnie SJ, et al. Manipulation and mobilisation for neck pain contrasted against an inactive control or another active treatment. Cochrane Database Syst Rev. 2015;9:CD004249.

86. Gross AR, Paquin JP, Dupont G, et al. Exercises for mechanical neck disorders: a Cochrane review update. Man Ther. 2016;24:25-45.

87. Verhagen AP, Scholten-Peeters GG, van Wijngaarden S, de Bie RA, Bierma-Zeinstra SM. Conservative treatments for whiplash. Cochrane Database Syst Rev. 2007;2:CD003338.

88. Patel KC, Gross A, Graham N, et al. Massage for mechanical neck disorders. Cochrane Database Syst Rev. 2012;9(9):CD004871.

89. Gross A, Forget M, St George K, et al. Patient education for neck pain. Cochrane Database Syst Rev. 2012;3:CD005106.

90. Malfliet A, Kregel J, Coppieters I, et al. Effect of pain neuroscience education combined with cognition-targeted motor control training on chronic spinal pain: a randomized clinical trial. JAMA Neurol. 2018; 75(7):808-817.

91. Van Hassel DTP, Kenens RJ. Cijfers uit de registratie van fysiotherapeuten. Peiling January 1, 2012. Available from: https://www.nivel.nl/sites/ default/files/bestanden/Cijfers-uit-de-registratie-van-fysiotherapeutenpeiling-jan-2012.pdf. Accessed June 28, 2018.

92. Scholten-Peeters GG, Neeleman-van der Steen CW, van der Windt DA, Hendriks EJ, Verhagen AP, Oostendorp RA. Education by general practitioners or education and exercises by physiotherapists for patients with whiplash-associated disorders? A randomized clinical trial. Spine. 2006;31(7):723-731
Patient Preference and Adherence

\section{Publish your work in this journal}

Patient Preference and Adherence is an international, peer-reviewed, open access journal that focuses on the growing importance of patient preference and adherence throughout the therapeutic continuum. Patient satisfaction, acceptability, quality of life, compliance, persistence and their role in developing new therapeutic modalities and compounds to optimize

\section{Dovepress}

clinical outcomes for existing disease states are major areas of interest for the journal. This journal has been accepted for indexing on PubMed Central. The manuscript management system is completely online and includes a very quick and fair peer-review system, which is all easy to use. Visit http://www. dovepress.com/testimonials.php to read real quotes from published authors. 